ARTICLE

httpst//doi.org/10.1038/s41467-020-14522-7

\title{
Post-functionalization of dibenzothiophene to functionalized biphenyls via a photoinduced thia-Baeyer-Villiger oxidation
}

\author{
Xiaofeng Ma1,2凶 , Yazhou $\mathrm{Liu}^{2}$, Le Du ${ }^{2,3}$, Jingwei Zhou ${ }^{4}$ \& István E. Markó ${ }^{2,5}$
}

The Baeyer-Villiger reaction is used extensively in organic chemistry. Sila- and bora-variants have also been documented widely, with these processes underpinning, for example, the Fleming-Tamao oxidation and hydroborative alkene hydration, respectively. By contrast, the development of thia-Baeyer-Villiger reactions involving sulfoxides has long been considered unlikely because competitive oxidation to the sulfone occurs exclusively. Here, we disclose a photoinduced thia-Baeyer-Villiger-type oxidations; specifically, we find that exposure of dibenzothiophene (DBT) derivatives to an iron porphyrin catalyst under Ultraviolet irradiation in the presence of $t-\mathrm{BuOOH}$ generates sulfinic esters in up to $87 \%$ yield. The produced sulfinic esters are transformed to a variety of biphenyl substrates including biphenyl sulfoxides, sulfones and sulfonamides in 1-2 steps. These results provide a mild process for the selective functionalization of sulfur compounds, and offer a biomimetic approach to convert DBT into 2-hydroxybiphenyl under controllable stepwise pathway. Based upon experimental evidences and DFT calculation, a mechanism is proposed.

\footnotetext{
${ }^{1}$ Natural Products Research Centre, Chengdu Institute of Biology, Chinese Academy of Sciences, 610041 Chengdu, People's Republic of China. ${ }^{2}$ Laboratory of Organic and Medicinal Chemistry, Université Catholique de Louvain, Place Louis Pasteur 1 bte L4. 01. 02, 1348 Louvain-la-Neuve, Belgium. ${ }^{3}$ Antibiotics Research and Re-evaluation Key Laboratory of Sichuan Province, Sichuan Industrial Institute of Antibiotics, Chengdu University, 610052 Chengdu, People's Republic of China. ${ }^{4}$ Institute of Clinical Pharmacology, Guangzhou University of Chinese Medicine, 510405 Guangzhou, People's Republic of China.

${ }^{5}$ Deceased: István E. Markó. ${ }^{凶}$ email: maxf@cib.ac.cn
} 
T

he Baeyer-Villiger oxidation involves the insertion of an oxygen atom into either the $\mathrm{C}-\mathrm{C}$ or $\mathrm{C}-\mathrm{H}$ bond of a carbonyl compound (i.e., aldehydes or ketones $\mathbf{1}$ ). The process is a particularly important transformation for the synthesis of esters $\mathbf{2}$ or carboxylic acids $\mathbf{2}^{\prime}$, and can be promoted by a wide variety of oxidants, including peracids and hydroperoxides (Fig. 1a) ${ }^{1-4}$. The regiochemical outcome of such reactions rests upon stringent stereo-electronic factors, and these have been elucidated by detailed mechanistic studies, which, in turn, allows regioselectivity to be predicted on a case-by-case basis ${ }^{2-4}$. In a related transformation, Brown reported that treatment of boranes
3 with basic hydrogen peroxide affords the corresponding borate esters 4 via a bora-analog of the Baeyer-Villiger rearrangement; subsequent hydrolysis generates the corresponding alcohols. This process is the final step of the alkenes hydroboration reaction, which effects the net anti-Markovnikov hydration of alkenes (Fig. 1b) $)^{5-7}$. Tamao and Fleming ${ }^{8-11}$ subsequently described the sila-version of the Baeyer-Villiger reaction. Depending upon the structure of the silane 5 , either hydroperoxides or peracids can be employed to promote oxidative rearrangement to the corresponding silyl ether 6 (Fig. 1c). The versatility, predictability, and mildness of these transformations accounts for their

a Baeyer-Villiger oxidation (A. Baeyer; V. Villiger 1899)

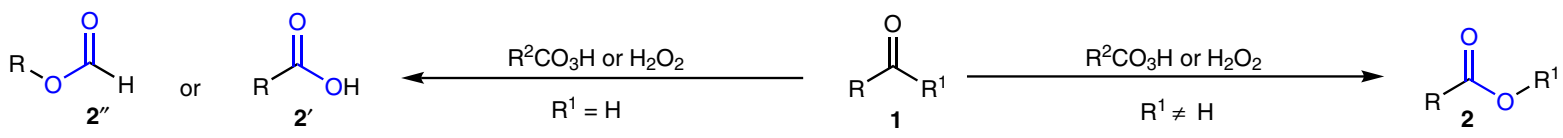

b Hydroboration-oxidation reaction (H. C. Brown, 1956)

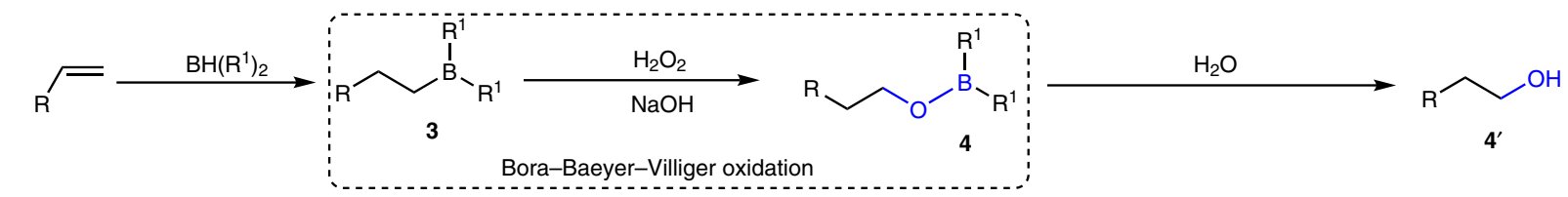

C Fleming-Tamao oxidation (K. Tamao, 1978, I. Fleming, 1984)

d The oxidation of sulfoxide
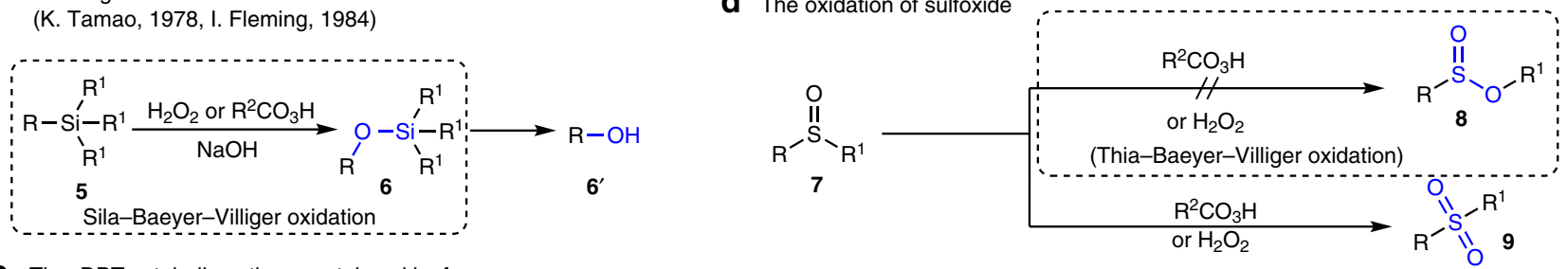

e The DBT catabolic pathway catalyzed by favoenzymes

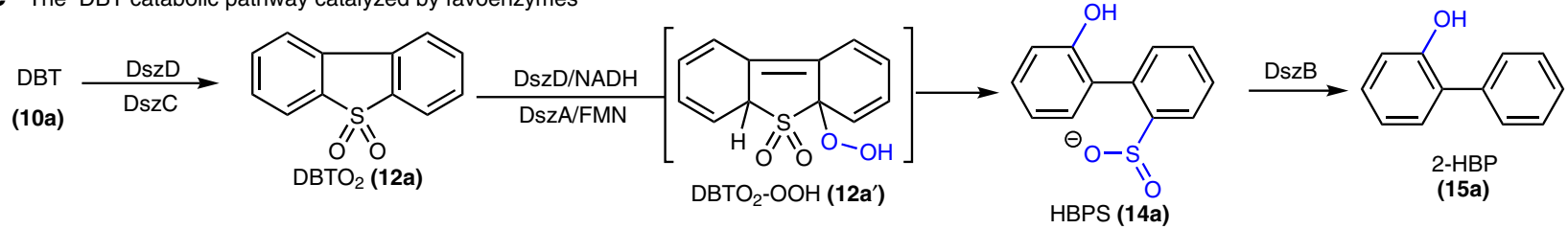

f This work (thia-Baeyer-Villiger oxidation)

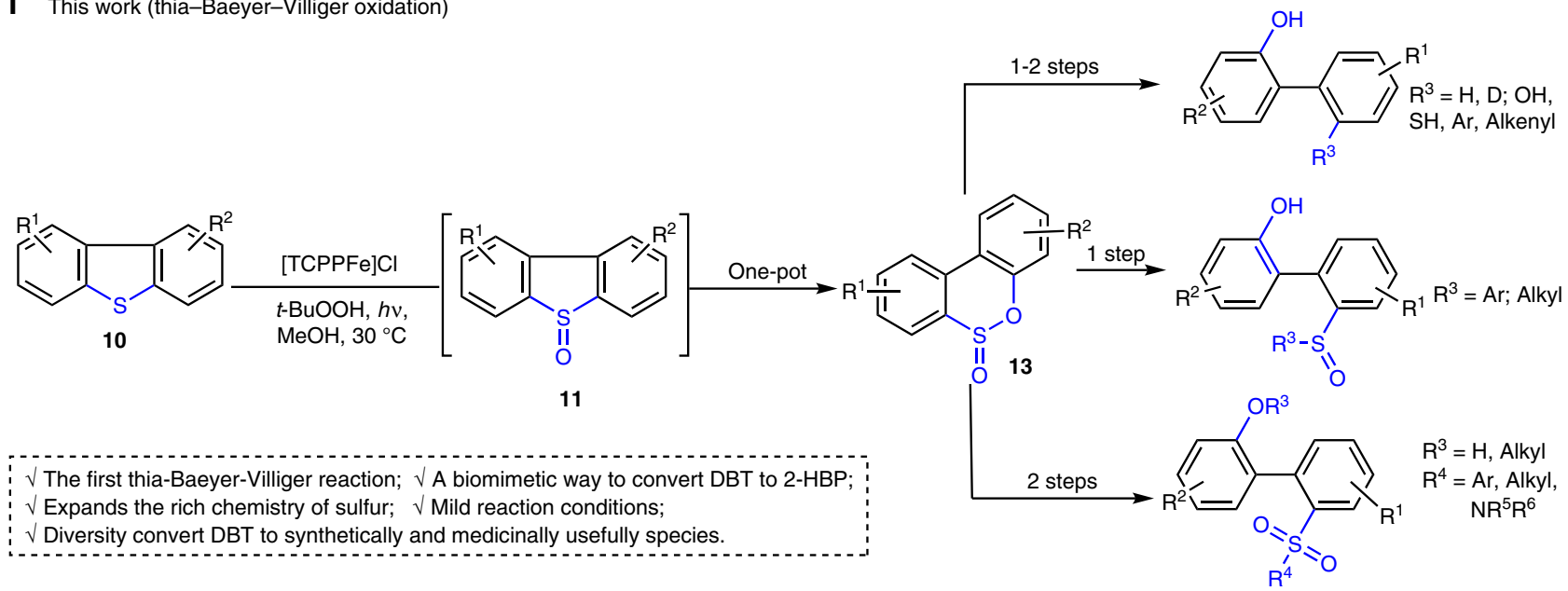

Fig. 1 Examples of oxygen insertion reactions. a Hydroperoxides or peracids promoted Baeyer-Villiger oxidation of ketone or aldehyde, which via oxygen insert to $\mathrm{C}-\mathrm{C}$ or $\mathrm{C}-\mathrm{H}$ bond. $\mathbf{b}$ Hydroboration oxidation of alkene, in which the last step via oxygen from hydroperoxides insert to C-B bond. $\mathbf{c}$ FlemingTamao oxidation through oxygen from hydroperoxides or peracids oxygen insert to C-Si bond. $\mathbf{d}$ In the presence of hydroperoxides or peracids, sulfoxide-carbon bond cannot take place oxygen insert reaction to produce sulfinic esters $\mathbf{8}$, but formed sulfone $\mathbf{9}$ via direct oxidation of sulfoxide. e DBT (10a) catabolic pathway catalyzed by Favoenzymes, in which oxygen from flavin hydroperoxide nucleophilic addition to $\mathrm{DBTO}_{2}$ formed $\mathrm{DBTO} \mathrm{O}_{2}-\mathrm{OOH}$. f Photoinduced thia-Baeyer-Villiger reaction, in which oxygen from $t-B u O O H$ insert to sulfoxide-carbon bonds (This work). DszA: DBT-5, $5^{\prime}$-dioxide $\left(\mathrm{DBTO}_{2}\right)$ monooxygenase, DszB: 2-(2'-hydroxyphenyl) benzenesulfinate (HBPS) desulfinase, DszC: DBT monooxygenase, DszD: flavin reductase, NADH: nicotinamide adenine dinucleotide, FMN: flavin mononucleotide. 
popularity in numerous synthetic ventures. In stark contrast, related oxygen atom insertion processes involving carbon sulfoxide bonds, to generate the corresponding sulfinic esters 8 , have not been reported, and, indeed, have long been considered a hopeless endeavor. Here, a lower energy pathway is available where the sulfoxide 7 is converted to the corresponding sulfone 9 (Fig. 1d) ${ }^{12,13}$. Even if such a thia-Baeyer-Villliger reaction could be achieved, it has been shown in certain cases that sulfinic esters 8 will rearrange to sulfones $\mathbf{9}$, which highlights a further challenge that must be overcome ${ }^{12}$.

Dibenzothiophene (DBT, 10a) and its methyl substituted derivatives, such as 4-methyl-dibenzothiophene and dimethyldibenzothiophenes (generally, 4,6-, 3,7-, and 2,8-dimethyl-DBTs), present as the major sulfur-containing heterocycles in crude petroleum. These are among the most recalcitrant compounds in deep desulfurization processes and can only be partially removed by conventional metal-catalyzed hydrodesulfurization (HDS) under high temperature and very high $\mathrm{H}_{2}$ pressure ${ }^{14,15}$. As a potential substitution for HDS, the biological desulfurization catalyzed by enzymes has drawn much attention in recent years due to its high selectivity, milder conditions, and lower $\mathrm{CO}_{2}$ emissions ${ }^{16-19}$. Among the developed biological desulfurization processes, the DBT catabolic pathway in Rhodococcus erythropolis has been well studied. In this process, DBT is initially oxidized to sulfone $\mathrm{DBTO}_{2}$ 12a via sulfoxide DBTO 11a. The resulting $\mathrm{DBTO}_{2}$ is subsequently converted to 2-(2-hydroxybiphenyl)-benzenesulfinate (HBPS, 14a) through a flavin hydroperoxide mediated rearrangement. Then, desulfurization of HBPS by desulfinase (DszB) forms 2-hydroxybiphenyl (2-HBP, 15a) (Fig. 1e $)^{18}$. Despite the great success in catabolization of DBT, the transformation still presents challenge of finding a microbial strain with high efficiency and broad scope of sulfur compounds, including substituted DBT derivatives. A biomimetic approach that can imitate the DBT catabolic pathway to efficiently convert DBT, especially its derivatives, to 2-HBP under mild conditions is thus highly desired.

In this article, we report our preliminary results on the discovery of a thia-Baeyer-Villiger reaction of DBT derivatives (10), leading to the corresponding sulfinic esters (13) via corresponding sulfoxides (11) (Fig. 1f). This demonstrates the feasibility of an oxygen insertion process into a sulfoxide-carbon linkage. Most notably, our observations expand the rich chemistry of sulfoxides and provide a biomimetic way to convert DBT and their derivatives to HBPS and 2-HBP under controllable condition, which offer an easy and efficient way for their conversion into other synthetically and medicinally useful products.

\section{Results}

Discovery and optimization of thia-Baeyer-Villiger oxidation. During studies on the biomimetic oxidation of DBT 10a catalyzed by the iron porphyrin complex [TCPPFe]Cl $(5,10,15,20$-Tetrakis (2-chlorophenyl)porphyrinato) iron (III) chloride) ${ }^{20-32}$, we observed that the initial oxidation product, sulfoxide DBTO 11a, underwent facile conversion to the corresponding sulfone $\mathrm{DBTO}_{2}$ $12 \mathbf{a}^{20}$. When this reaction was run on larger scale, we were able to isolate small amounts of an unknown compound possessing the same molecular formula $\left(\mathrm{C}_{12} \mathrm{H}_{12} \mathrm{SO}_{2}\right)$ as sulfone $\mathrm{DBTO}_{2} \mathbf{1 2 a}$. Spectroscopic analysis indicated that this product was nonsymmetrical and it was assigned as sulfinic ester (BPS, 13a) by comparison to data reported by $\mathrm{Crich}^{33}$, who prepared this compound via a different synthetic route. Finally, single crystal Xray diffraction analysis of related sulfinic ester 13e, which was prepared in a manner analogous to BPS, unambiguously established the structures of these thia-Baeyer-Villiger products (see Table 2).
That such an oxidative insertion process took place under mild conditions was truly exciting. Various attempts to improve the yield of BPS 13a by varying different reaction parameters met with failure. Ultimately, a key observation was made when the reaction was run in the dark, as, under these conditions, only sulfide DBT 10a was recovered in $92 \%$ yield (Table 1 , entry 2 ). It was thus evident that light is necessary for the formation of BPS 13a. Indeed, irradiation of a methanol solution containing the iron porphyrin catalyst and DBT 10a using a 250 Watt highpressure $\mathrm{Hg}$ lamp in the presence of 6.0 equiv. of $t$ - $\mathrm{BuOOH}$ provided sulfinic ester BPS 13a in $86 \%$ yield (Table 1, entry 1 , see Supplementary Figs. 3-9 for reaction progress monitored by HPLC). No product was formed when the reaction was performed under omission of the catalyst TCPPFeCl (Table 1, entry 3). Similarly, the corresponding manganese porphyrin catalyst was not effective and gave only trace amount of desired product (Table 1 , entry 4 ). The other iron porphyrin catalysts, including $\left[\mathrm{T}\left(o-\mathrm{NO}_{2}\right) \mathrm{PPFe}\right] \mathrm{Cl},\left[\mathrm{T}\left(o-\mathrm{NH}_{2}\right) \mathrm{PPFe}\right] \mathrm{Cl}$, and $[\mathrm{TPPFe}] \mathrm{Cl}$ were also tested, which afforded the target product in $15 \%-62 \%$ yield. (Table 1, entries 5-7). Increasing $t$-BuOOH did not improve yield (Table 1 , entry 1 vs entry 10 ), but decreasing it resulted in reducing the yield dramatically (Table 1 , entry 1 vs. entries 8,9 ). Lastly, changing the power of light only increased the yield of oxidized product $\mathrm{DBTO}_{2}$ (Table 1 , entries 11 and12). Furthermore, the reaction can start from DBTO directly in the presence of 4.0 equiv. of $t-\mathrm{BuOOH}$, under those condition, the target product was isolated in $84 \%$ yield (Table 1 , entry 13 , see Supplementary Figs. 10-14 for reaction progress monitored by HPLC).

Substrate scope of thia-Baeyer-Villiger oxidation. At this stage, the new protocol was applied to a range of aromatic sulfides and salient results are displayed in Table 2. As can be seen, the reaction tolerates a variety of substituents, ranging from alkyl groups to benzylic alcohols (10f), ethers $(\mathbf{1 0 h}, \mathbf{1 0 i})$ and alkenes (10i). Placement of a methyl substituent at the 4-position (10b) had little impact on the yield of the reaction; however, the nonsymmetrical nature of the starting material $\mathbf{1 0 b}$ resulted in the formation of two isomeric sulfinic esters, $\mathbf{1 3 b}$ and 13b' (Table 2, entry 3). Sulfide 10c, which possesses methyl groups at the $\mathrm{C} 4$ and C6 positions, provided a decreased in the yield of $13 \mathbf{c}$, indicating that the process is sensitive to sterics (Table 2, entry 5). However, it is worth noting that $\mathbf{1 0 c}$ is a particularly inert substrate, and its desulfurization, even under stringent conditions, proceeds in only marginal yields ${ }^{14}$. That adduct $13 \mathrm{c}$ could be formed in 55\% yield is a clear testimony to the power of this oxidative rearrangement process. Systems with methyl groups at other positions delivered the desired sulfinic esters in good to excellent yields (Table 2, entries 7 and 9). Notably, when corresponding sulfoxides (11a-11d) were used as the starting materials, the thia-Baeyer-Villiger oxidation maintained the same efficiency (Table 2, entry 1 vs. entry 2; entry 3 vs. entry 4; entry 5 vs. entry 6). Sulfide 10f, which contains an unprotected benzylic alcohol, underwent thia-Baeyer-Villiger rearrangement to provide regioisomers $\mathbf{1 3 f}$ and $\mathbf{1 3} \mathbf{f}^{\prime}$ in a $1: 1$ ratio (Table 2, entry 10 ). Benzylic ether containing sulfides $\mathbf{1 0 h}$ and $\mathbf{1 0} \mathbf{i}$ afforded oxidized products $13 \mathrm{~h}$ and $\mathbf{1 3 i}$ in $70 \%$ and $62 \%$ yield, respectively (Table 2, entries 12 and 13). Highly electron-rich sulfide $\mathbf{1 0 j}$, could also be oxidized to provide sulfinic ester $\mathbf{1 3} \mathbf{j}$, albeit in modest yield (Table 2, entry 14). A current limitation of the method involves electron-deficient sulfides, as evidenced by substrate 10k, which did not provide thia-Baeyer-Villiger product $\mathbf{1 3 k}$ (Table 1, entry 15), while the corresponding sulfoxide $11 \mathbf{k}$ was subjected to the standard conditions, deoxygenation of the sulfoxide occurred in $89 \%$ yield (Table 1 , entry 16 ). 
Table 1 Optimization of the thia-Baeyer-Villiger reaction.

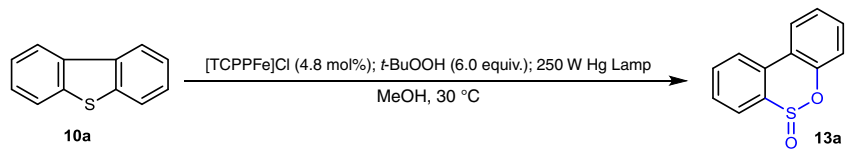

\begin{tabular}{|c|c|c|}
\hline Entry & Variations from standard conditions & Yield of BPS \\
\hline 1 & None & $86 \%$ \\
\hline 2 & No light & $0^{b}$ \\
\hline 3 & No $[\mathrm{TCPPFe}] \mathrm{Cl}$ & $0^{c}$ \\
\hline 4 & {$[\mathrm{TCPPMn}] \mathrm{Cl}$ instead of $[\mathrm{TCPPFe}] \mathrm{Cl}$} & trace \\
\hline 5 & {$[\mathrm{TPPFe}] \mathrm{Cl}$ instead of $[\mathrm{TCPPFe}] \mathrm{Cl}$} & $39 \%$ \\
\hline 6 & {$\left[\mathrm{~T}\left(\mathrm{o}-\mathrm{NH}_{2}\right) \mathrm{PPFe}\right] \mathrm{Cl}$ instead of $[\mathrm{TCPPFe}] \mathrm{Cl}$} & $15 \%$ \\
\hline 7 & {$\left[\mathrm{~T}\left(\mathrm{o}-\mathrm{NO}_{2}\right) \mathrm{PPFe}\right] \mathrm{Cl}$ instead of $[\mathrm{TCPPFe}] \mathrm{Cl}$} & $62 \%$ \\
\hline 8 & $t-\mathrm{BuOOH}(2.0 \mathrm{eq})$ & $33 \%$ \\
\hline 9 & $t$-BuOOH (4.0 eq) & $63 \%$ \\
\hline 10 & $t-\mathrm{BuOOH}(8.0 \mathrm{eq})$ & $87 \%$ \\
\hline 11 & 500 W Hg Lamp & $63 \% d$ \\
\hline 12 & 150 W Hg Lamp & $69 \% \mathrm{e}$ \\
\hline 13 & From DBTO 11a and $t-\mathrm{BuOOH}$ (4.0 eq) & $84 \%$ \\
\hline
\end{tabular}
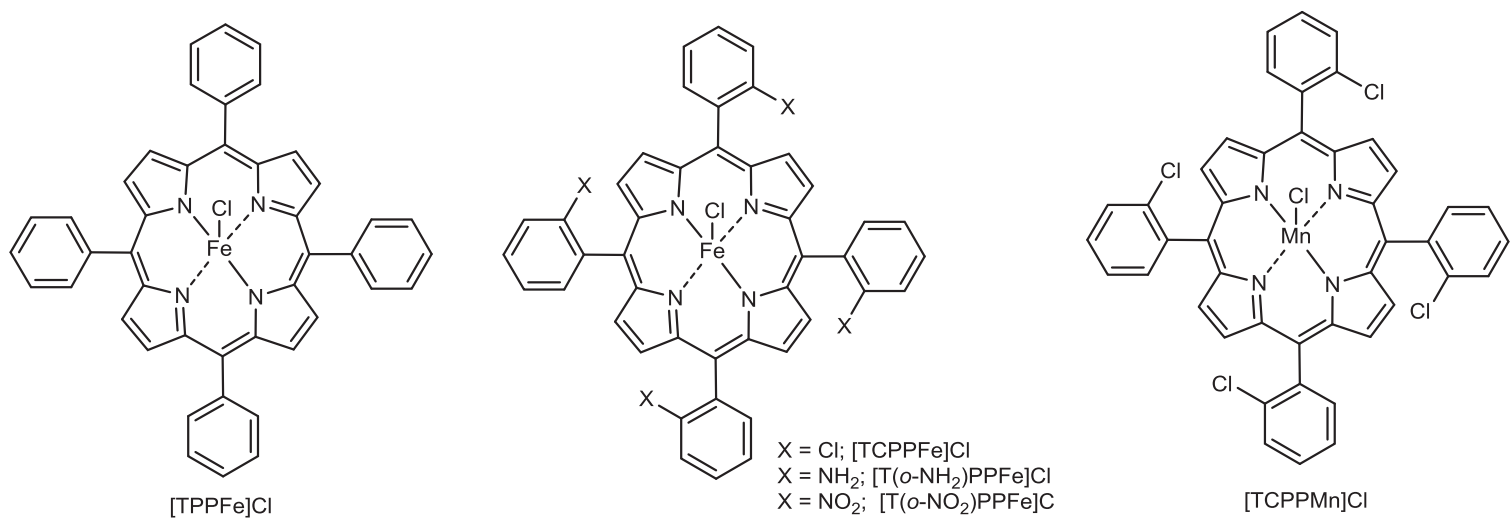

${ }^{a}$ Isolated yield.

DDBT was recovered in $92 \%$ yield.

cNo reaction.

${ }^{d} \mathrm{DBTO}_{2}$ was isolated in $30 \%$ yield.

e ${ }^{\mathrm{DBTO}} 2$ was isolated in $21 \%$ yield. [TPPFe]Cl: meso-tetraphenylporphinatoiron (III) chloride; [TCPPFe]Cl: $(5,10,15,20$-Tetrakis(2-chlorophenyl) porphyrinato) iron (III) chloride); [T(o-NH $\mathbf{2}) \mathbf{P P F e}$ Cl: (5,10,15,20-Tetrakis(2-amino)porphyrinato) iron (III) chloride); [T(o-NO $\mathbf{2}_{\mathbf{2}}$ )PPFe]Cl: (5,10,15,20-Tetrakis(2-nitro)porphyrinato) iron (III) chloride); [TCPPMn]Cl: (5,10,15,20-Tetrakis(2-chlorophenyl) porphyrinato)manganese (III) chloride.

Mechanistic investigations of thia-Baeyer-Villiger oxidation. The photochemical behavior of DBTO and the corresponding sulfone $\mathrm{DBTO}_{2}$ has been investigated extensively ${ }^{34}$. The seminal work of Jenks ${ }^{35-39}$, Greer ${ }^{40,41}$, Nakai ${ }^{42}$, Shiraishi ${ }^{43,44}$, and oth$\mathrm{ers}^{45}$ has provided important mechanistic insights and enabled the establishment of a general reaction framework that rationalizes the formation of various products observed during photochemical processes involving these compounds. In all cases, it has been established that irradiation of DBTO results in cleavage of the sulfoxide $\mathrm{S}-\mathrm{O}$ bond to release sulfide DBT and atomic oxygen $\mathrm{O}\left({ }^{3} \mathrm{P}\right)$, which oxidizes the solvent. In certain cases, sulfinic ester has been observed, but only in trace amounts ${ }^{46,47}$. It was found that biphenylsultone, an overoxidation product of 13a was formed in less than $5 \%$ yield in a catalytic oxidation of DBT by metal-sulfophthalocyanines catalysts in the presence of $\mathrm{H}_{2} \mathrm{O}_{2}$ or monopersulfate $e^{48}$. Hence, it appears that the porphyrin catalyst [TCPPFe]Cl is critical for the diversion of the reaction pathway towards thia-Baeyer-Villiger product sulfinic ester. Indeed, UV-Vis (Ultraviolet-visible) spectroscopy (Supplementary Fig. 15a) showed that upon addition of sulfoxide DBTO to [TCPPFe]Cl in the presence of $t-\mathrm{BuOOH}$, a [DBTO-TCPPFe.t-
$\mathrm{BuOOH}] \mathrm{Cl}$ complex was formed. When this complex was irradiated, a mixture of sulfinic ester and sulfide DBT was generated. Addition of imidazole to the same reaction solution, followed by irradiation, provided the desired product BPS in only $44 \%$ yield (HPLC yield) (Supplementary Table 1, entry 2) (See Supplementary Fig. 15b for UV-Vis spectroscopy). Imidazole is a good axial ligand for [TCPPFe] $\mathrm{Cl}^{24,49,50}$ and would be expected to displace rapidly DBTO from the metal complex. Consequently, the decrease of reactivity observed in the presence of imidazole indicates that the formation of a [DBTO-TCPPFe- $t$-BuOOH]Cl complex is a compulsory step in the successful generation of BPS (see Supplementary Figs. 17-21 for reaction progress monitored by HPLC).

Control experiments. A range of experiments were then performed to clarify the mechanism of the thia-Baeyer-Villiger reaction (Supplementary Table 1). Started from DBTO, in the absence of light (under air atmosphere, with PhIO as oxidant), only $\mathrm{DBTO}_{2}$ from the oxidation of DBTO was formed in $89 \%$ yield (Supplementary Table 1, entry 3 ), and lack of $t$-BuOOH and 
Table 2 Scope of the Thia-Baeyer-Villiger Reaction.

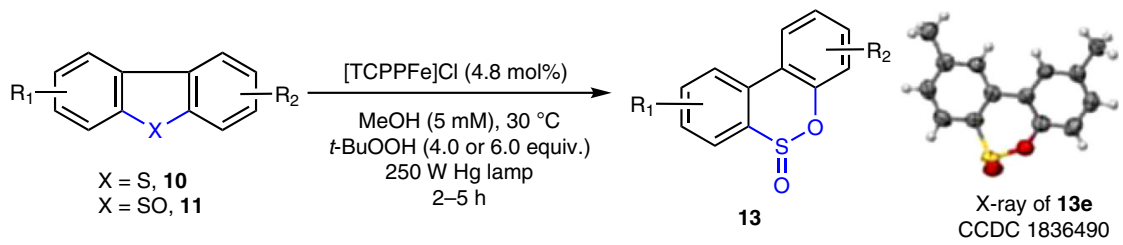

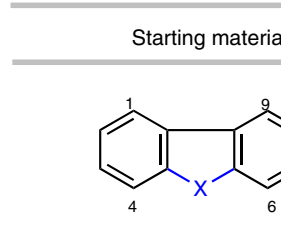

$$
\text { (1) } X=S ; 10 a
$$$$
\text { (2) } X=S O ; 11 a
$$<smiles>[X]c1c(C)cccc1-c1cccc(C)c1</smiles>

$$
\begin{aligned}
& \text { (5) } X=S ; 10 c \\
& \text { (6) } X=S O ; 11 c
\end{aligned}
$$<smiles>Cc1ccc2sc3ccc(C)cc3c2c1</smiles>

(9) $\quad 10 \mathrm{e}$<smiles>CCCCc1ccc2sc3ccc(CCCC)cc3c2c1</smiles>

(11)

$$
10 \mathrm{~g}
$$<smiles>CCOCc1ccc2sc3ccc(COCCOCCOCCOCc4ccccc4)cc3c2c1</smiles>

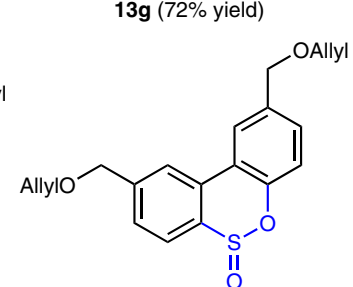

(13) $10 \mathrm{i}$<smiles>CC(=O)c1ccc2sc3ccccc3c2c1</smiles>

(15) 10k<smiles>O=[PH](O)c1ccccc1OS(=O)c1ccccc1</smiles>

13a (86\% yield) 13a (84\% yield)<smiles>Cc1cccc2c1OS(=O)c1c(C)cccc1-2</smiles>

\section{3c $\left(55 \%\right.$ yield $\left.^{b}\right)$} $13 \mathrm{c}\left(48 \%\right.$ yield $\left.^{c}\right)$<smiles>Cc1ccc2c(c1)-c1cc(C)ccc1S(=O)O2</smiles>

13 e $(82 \%$ yield)<smiles>CCCCc1ccc2c(c1)-c1cc(CCCC)ccc1S(=O)O2</smiles>

$13 g(72 \%$ yield $)$<smiles>[X]c1ccccc1-c1cccc(C)c1</smiles>

(3) $X=S ; 10 b$

(4) $X=S O ; 11 b$
Product<smiles>Cc1cccc2c1S(=O)Oc1ccccc1-2</smiles><smiles>Cc1cccc2c1OS(=O)c1ccccc1-2</smiles>

$13 b$

(13b:13b' $=1: 1^{a}, 87 \%$ yield) (13b:13b' $=1: 1^{a}, 86 \%$ yield $)$ 


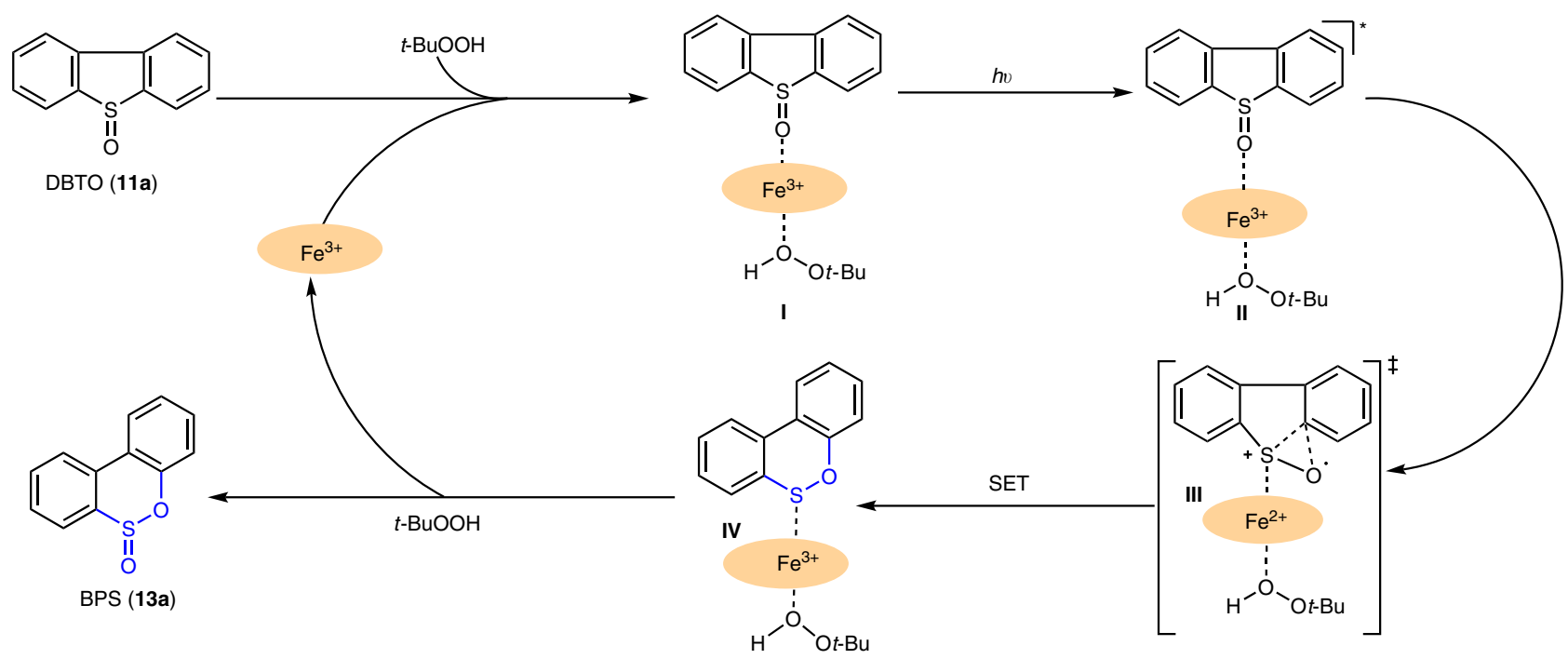

Fig. 2 A plausible mechanism for the thia-Baeyer-Villiger reaction. SET: single-electron transfer.<smiles>COS(=O)c1ccc(C)cc1-c1cc(C)c(O)cc1O</smiles><smiles>CC(=O)CCc1cc(O)c(-c2cccc(C)c2)cc1C</smiles><smiles>O=S1Oc2ccccc2-c2ccccc21</smiles>

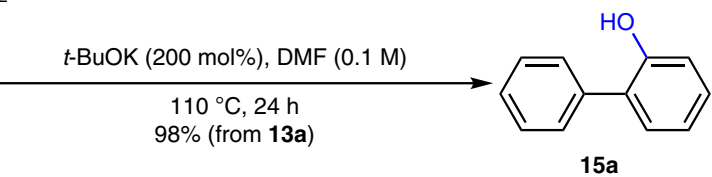

Fig. 3 Biomimetic desulfurization. In KPi buffer or in the presence of bases, sulfinic esters (13a and 13e) were smoothly converted to HBPS or 2-HBP derivatives. KPi buffer: potassium phosphate buffer.

(or) catalyst led to reduce of DBTO to DBT (Supplementary Table 1, entries 4-6). The reaction was inhibited dramatically by radical quenchers such as (2,2,6,6-tetramethylpiperidin-1- yl)oxyl (TEMPO) and butylated hydroxytoluene (BHT) suggested a radical pathway (Supplementary Table 1, entries $7-10)^{51-53}$. Furthermore, addition of 1.0 equiv. of $\mathrm{CuCl}_{2}$ to the reaction mixture resulted in the formation of BPS in 59\% yield (HPLC yield) (Supplementary Table 1, entry 11), which revealed a singleelectron processes may be involved in this photochemical process $^{51-53}$.

Mechanism and DFT calculations. Based on the observations outlined above, we propose a plausible reaction mechanism for the thia-Baeyer-Villiger reaction (Fig. 2). Starting from sulfide $\mathrm{DBT}$, the $\mathrm{Fe}$ porphyrin complex and $t$ - $\mathrm{BuOOH}$ effect initial oxidation to sulfoxide $\mathrm{DBTO}^{20}$. Ligation of DBTO to the Fe center of $[\mathrm{TCPPFe}] \mathrm{Cl}$ forms complex I. At this stage, photochemical irradiation of $\mathbf{I}$ forms excited state $\mathbf{I I}^{52,54,55}$, which undergoes $\mathrm{C}-\mathrm{S}$ bond cleavage with concomitant $\mathrm{C}-\mathrm{O}$ bond formation, leading to iron-coordinated sulfenic ester species IV via transition state III. Computational studies (Supplementary Fig. 72 and Supplementary Table 2) revealed that DBTO could directly isomerize to sulfenic ester IV without the Fe porphyrin via high-energy transition state $(47.0 \mathrm{kcal} / \mathrm{mol})$. However, the energy barrier was significantly lower $(15.7 \mathrm{kcal} / \mathrm{mol})$, in the presence of the Fe porphyrin complex (see III in Supplementary Fig. 72 and Supplementary Table 2). Thus, the process from II to IV is facilitated by the porphyrin Fe catalyst, via either a weakening of the C-S bond of III or stabilization of radical cation III. Either way, deviation of the process from established pathways (vide supra) requires smooth formation of intermediate $\mathbf{I V}^{56,57}$ rather than the formation of $\mathrm{O}\left({ }^{3} \mathrm{P}\right)^{35-41,47}$. From sulfenic ester IV, oxidation, presumably by an $\mathrm{Fe} / \mathrm{t}-\mathrm{BuOOH}$ complex, affords sulfinic ester and releases the iron catalyst to re-enter the catalytic cycle.

A biomimetic desulfurization processes. In the biocatalytic desulfurization process depicted in Fig. 1e, DBT (10a) was oxidized to $\mathrm{DBTO}_{2}$ (12a) by DBT monooxygenase (DszC), which was further transformed to HBPS (14a) by $\mathrm{DBTO}_{2}$-monozygenase (DszA), the produced 14a was then desulfurized by desulfinase (DszB) forms 2-hydroxybiphenyl (2-HBP) $(\mathbf{1 5 a})^{18}$. An analogous transformation can be achieved using the developed thia-Baeyer-Villiger methodology, as the rearrangement products sulfinic esters (for example, 13a and 13e) can easily hydrolyze into HBPS derivatives 14a and 14e in $92 \%$ and $95 \%$ yield when exposed to KPi buffer (Fig. 3) ${ }^{18}$. Alternatively, when 13a and 13e were heated in the presence of base in polar solvents, the corresponding desulfurized products 2-HBPs were formed in excellent yields (15a and 15e, 98\% and 93\% yield, respectively). 


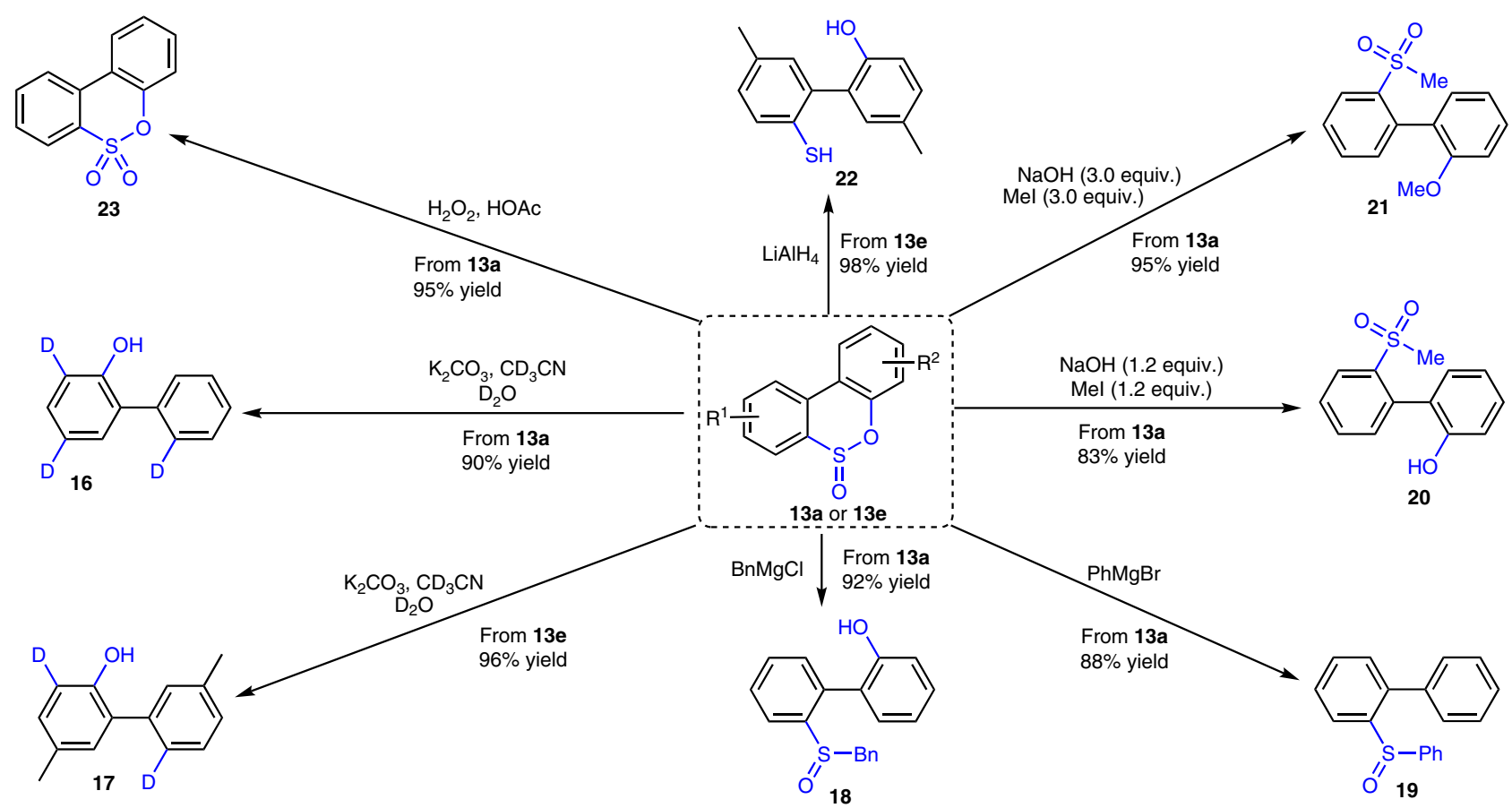

Fig. 4 Diverse transform of sulfinic esters. Sulfinic esters 13a and 13e were transformed to medicinally and synthetically useful products 16-23.

Diverse transformation of sulfinic esters. By combination of the developed thia-Baeyer-Villiger rearrangement with the baseinduced desulfurization process, we successfully imitated the biocatalytic desulfurization process and convert DBT into 2-HBP in an efficient way, however, different from biocatalytic desulfurization, our method proceeded under a controllable stepwise conditions, thus, if necessary, the product from thiaBaeyer-Villiger reaction can be convert to a vast array of medicinally and synthetically useful intermediates (Fig. 4). Indeed, when sulfinic esters were treated with base in a deuterated solvent in presence of $\mathrm{D}_{2} \mathrm{O}$, the corresponding deuterated products (16 and 17) were isolated in excellent yields $(90 \%$ and $96 \%$, respectively). Otherwise, when BPS 13a was reacted with alkyl and aryl Grignard reagents, the biphenyl sulfoxides (18 and 19) were formed in $88 \%$ and $92 \%$ yields, respectively. Furthermore, the sulfinic ester is a dual electrophilic and nucleophilic functional group, it can react with nucleophiles and electrophiles under controllable conditions. For example, when BPS was first treated with nucleophilic $\mathrm{NaOH}$, which was followed by the addition of electrophilic MeI, the biphenyl sulfone was generated in good yield, by control amount of $\mathrm{NaOH}$ and $\mathrm{MeI}$, one can control the distribution of the product from 2-hydroxybiphenyl $20(83 \%$ yield) to 2-methoxybiphenyl 21 (95\% yield). Besides, the sulfur (IV) in sulfinic ester can take place facilely oxidation and reduction reaction, thus, when treated BPS with $\mathrm{LiAlH}_{4}$, the reduced product thiol-biphenol 22 was obtained in 98\% yield, while $\mathrm{H}_{2} \mathrm{O}_{2}$ in HOAc efficiently oxidized BPS to biphenylsultone 23 in $95 \%$ yield $^{58}$.

Transformation of 23 to biphenyl sulfones and sulfonamides. Considering the prevalence of sulfones and sulfonamides in medicinal chemistry, the potential application of the current methodology was further demonstrated by transformation of biphenylsultone to a range of biphenyl sulfones and sulfonamides (Table 3). For example, when biphenylsultone $\mathbf{2 3}$ was submitted to aryl and alkyl lithium reagents, the corresponding biphenyl sulfones were obtained in good yields (24a and $24 \mathbf{b}, 62 \%$ and $65 \%$ yield, respectively), while subjected sultone $\mathbf{2 3}$ to a solution lithium amide, the sulfonamides $(\mathbf{2 4 c}-\mathbf{2 4 f})$ were produced in $85 \%$ to $99 \%$ yields.

Transformation of 2-HBPs to substituted biphenyl. Lastly, the desulfurized product 2-HBPs $\mathbf{1 5}$ are also useful building blocks for hydroxyl-directed $\mathrm{C}-\mathrm{H}$ bond activation as exemplified in Table $4^{59}$. As described by Fan and co-workers ${ }^{60}$, in the presence of $t$ - $\mathrm{BuOOH}, 2$ 2-biphenol was obtained in $76 \%$ yield from 2 $\mathrm{HBP}$ via a $\mathrm{Pd}(\mathrm{OAc})_{2}$ catalyzed $\mathrm{C}-\mathrm{H}$ bond hydroxylation. Similarly, 15e was converted to $\mathbf{2 5 b}$ and $\mathbf{2 5 c}$ in $62 \%$ and $48 \%$ yield, respectively, by $\mathrm{Pd}(\mathrm{OAc})_{2}$ catalyzed $\mathrm{C}-\mathrm{H}$ bond arylation and alkenylation.

\section{Discussion}

We have discovered an efficient thia-Baeyer-Villiger oxidation that enables the conversion of sulfides to sulfinic esters via the corresponding sulfoxides by an iron porphyrin catalyst under UV irradiation. The process provides a mild way for the selective functionalization of sulfur. Our methodology successfully imitated the DBT catabolic pathway in Rhodococcus erythropolis to convert DBT into 2-HBP under a controllable and efficient stepwise pathway, which was beneficial to a wide range of further transformation. By maximum three steps, DBT and their derivatives were transformed to a wide range of biphenyl substrates, such as biphenyl thiol, sulfoxides, sulfones, sulfonamides, and 2,2biphenols. Mechanism research shows that the photoinduced thia-Baeyer-Villiger oxidation may take place via a radical cation pathway.

\section{Methods}

General procedures for thia-Baeyer-Villiger reaction of DBT. To a stirring solution of DBT or their derivatives $(0.15 \mathrm{mmol})$ and [TCPPFe]Cl $(6 \mathrm{mg}$, $4.8 \mathrm{~mol} \%)$ in $\mathrm{MeOH}(30 \mathrm{~mL})$ was added 6.0 equiv. of $t$-BuOOH $(160 \mu \mathrm{L}, 5.5 \mathrm{M}$ in decane) over $5 \mathrm{~min}$ at $30^{\circ} \mathrm{C}$ (bath temperature) (the bath temperature may rise to $35^{\circ} \mathrm{C}$ during reaction), the resulted mixture was exposed to $250 \mathrm{~W}$ high-pressure mercury lamp, after the reaction was complete $(2-3 \mathrm{~h})$ as judged by thin-layer chromatography analysis, the solvent was removed under reduced pressure to give 


\section{Table 3 Synthesis of biphenyl sulfones and sulfonamides. ${ }^{a}$}

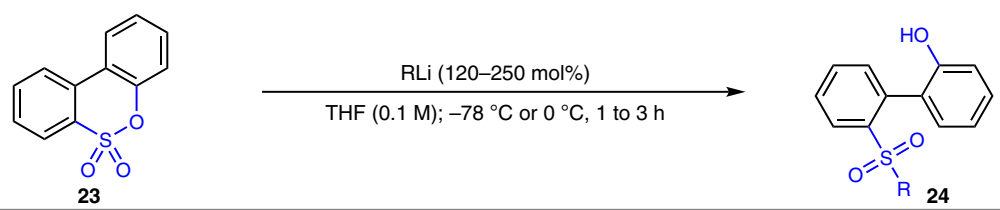

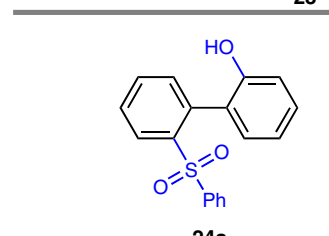

PhLi (120 mol\%); $62 \%$ yield

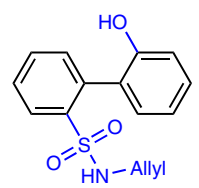

24d

Allyamine (200 mol\%), $n$-BuLi (210 mol\%); $97 \%$ yield

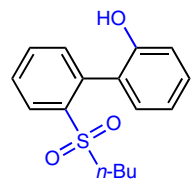

24b $n$-BuLi (250 mol\%); $65 \%$ yield

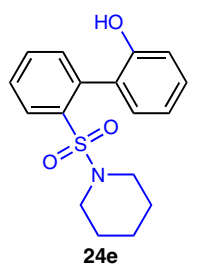

Piperidine (200 mol\%), n-BuLi (210 mol\%); $96 \%$ yield<smiles>O=S(=O)(NCc1ccccc1)c1ccccc1-c1ccccc1O</smiles>

$24 \mathrm{c}$

$\mathrm{BnNH}_{2}$ (200 mol\%), $n$-BuLi (210 mol\%); $85 \%$ yield

alsolated yield

Table 4 Hydroxyl-directed C-H bond activation. ${ }^{a}$

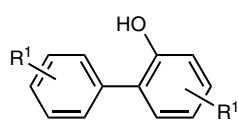

15
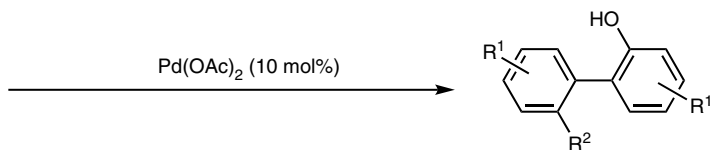

25<smiles>Oc1ccccc1-c1ccccc1O</smiles>

25a

With $t-\mathrm{BuOOH} ; 76 \%$ yield $^{\text {ref } 60}$

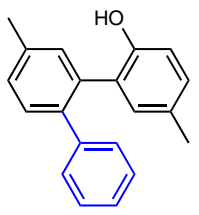

25b

With $\mathrm{Phl}^{b} ; 62 \%$ yield

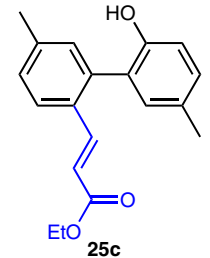

With Ethyl acrylate ${ }^{c} ; 48 \%$ yield

${ }^{a}$ Isolated yield

beaction conditions: $\mathrm{Pd}(\mathrm{OAc})_{2}(10 \mathrm{~mol} \%), \mathrm{Phl}(120 \mathrm{~mol} \%), \mathrm{Cs}_{2} \mathrm{CO}_{3}(120 \mathrm{~mol} \%), \mathrm{DMF}(0.2 \mathrm{M}), 100^{\circ} \mathrm{C}, 24 \mathrm{~h}$.

CReaction conditions: $\mathrm{Pd}(\mathrm{OAc})_{2}(10 \mathrm{~mol} \%)$, ethyl acrylate $(200 \mathrm{~mol} \%), 1,4$-benzoquinone $(100 \mathrm{~mol} \%), \mathrm{HOAc}(0.5 \mathrm{M}), 80^{\circ} \mathrm{C}, 24 \mathrm{~h}$

the crude product, which was purified by flash $\mathrm{SiO}_{2}$ gel column chromatography to obtain the product.

\section{Data availability}

The authors declare that full experimental details, mechanistic studies, UV-Vis spectra and characterization of compounds are available in the Supplementary Information. The X-ray crystallographic data for compound 13e reported in this study has been deposited at the Cambridge Crystallographic Data Center (CCDC), under deposition number 1836490. These data can be obtained free of charge from The Cambridge Crystallographic Data Center via www.ccdc.cam.ac.uk/data_request/cif. All other data are available from the authors upon reasonable request.

Received: 24 May 2019; Accepted: 11 November 2019; Published online: 14 February 2020

\section{References}

1. Baeyer, A. \& Villiger, V. Einwirkung den caro'sohen reagens auf ketone. Ber. Dtsch. Chem. Ges. 32, 3262-3265 (1899).

2. Krow, G. R. The Bayer-Villiger oxidation of ketones and aldehydes. Org. React. 43, 251-798 (1993).

3. Renz, M. \& Meunier, B. 100 years of Baeyer-Villiger oxidations. Euro. J. Org. Chem. 737-750 (1999).

4. Ten Brink, G. -J., Arends, I. W. C. E. \& Sheldon, R. A. The Baeyer-Villiger reaction: new developments toward greener procedures. Chem. Rev. 104, 4105-4123 (2004).

5. Brown, H. C. \& Rao, B. C. S. A new technique for the conversion of olefins into organoboranes and related alcohols. J. Am. Chem. Soc. 78, 5694-5695 (1956).

6. Brown, H. C. \& Rao, B. C. S. Communications-selective conversion of olefins into organoboranes through competitive hydroboration, isomerization and displacement reactions. J. Org. Chem. 22, 1137-1138 (1957). 
7. Smith, K. in Organometallics in Synthesis (a Manual) 2nd edn (ed. Schlosser, M.) 465-533 (Wiley, Chichester, 2002).

8. Tamao, K., Kakui, T. \& Kumada, M. Organofluorosilicates in organic synthesis. 2. A convenient procedure for preparing primary alcohols from olefins. A novel facile oxidative cleavage of carbon-silicon bonds by $m$ chloroperoxybenzoic acid. J. Am. Chem. Soc. 100, 2268-2269 (1978).

9. Tamao, K. et al. Oxidative cleavage of silicon-carbon bonds in organosilicon fluorides to alcohols. Tetrahedron 39, 983-990 (1983).

10. Fleming, I., Henning, R. \& Plaut, H. The phenyldimethylsilyl group as a masked form of the hydroxy group. J. Chem. Soc. Chem. Commun. 29-31 (1984).

11. Fleming, I., Barbero, A. \& Walter, D. Stereochemical control in organic synthesis using silicon-containing compounds. Chem. Rev. 97, 2063-2192 (1997).

12. Patai, S. \& Rappoport, Z. The Synthesis of Sulfones, Sulfoxides, and Cyclic Sulfides (Wiley, 1994).

13. Sato, K., Hyodo, M., Aoki, M., Zheng, X. -Q. \& Noyori, R. Oxidation of sulfides to sulfoxides and sulfones with $30 \%$ hydrogen peroxide under organic solvent- and halogen-free conditions. Tetrahedron 57, 2469-2476 (2001).

14. Campos-Martin, J. M., Capel-Sanchez, M. C., Perez-Presas, P. \& Fierro, J. L. G. Oxidative processes of desulfurization of liquid fuels. J. Chem. Technol. Biotechnol. 85, 879-890 (2010).

15. Javadli, R. \& De Klerk, A. Desulfurization of heavy oil. Appl. Petrochem. Res. 1, 3-19 (2012).

16. McFarland, B. L. Biodesulfurization. Curr. Opin. Microbiol. 2, 257-264 (1999).

17. Soleimani, M., Bassi, A. \& Margaritis, A. Biodesulfurization of refractory organic sulfur compounds in fossil fuels. Biotechnol. Adv. 25, 570-596 (2007).

18. Adak, S. \& Begley, T. P. Dibenzothiophene catabolism proceeds via a flavin$\mathrm{N}_{5}$-oxide intermediate. J. Am. Chem. Soc. 138, 6424-6426 (2016).

19. Gray, K. A. et al. Molecular mechanisms of biocatalytic desulfurization of fossil fuels. Nat. Biotechnol. 14, 1705-1709 (1996).

20. Zhou, X., Chen, X., Jin, Y. \& Markó, I. E. Evidence of two key intermediates contributing to the selectivity of P450-biomimetic oxidation of sulfides to sulfoxides and sulfones. Chem. Asian J. 7, 2253--22257 (2012).

21. Meunier, B. Metalloporphyrins as versatile catalysts for oxidation reactions and oxidative DNA cleavage. Chem. Rev. 92, 1411-1456 (1992).

22. Che, C. M. \& Huang, J. S. Metalloporphyrin-based oxidation systems: from biomimetic reactions to application in organic synthesis. Chem. Commun. 21, 3996-4015 (2009).

23. Calvete, M. J., Piñeiro, M., Dias, L. D. \& Pereira, M. M. Hydrogen peroxide and metalloporphyrins in oxidation catalysis: old dogs with some new tricks. ChemCatChem. 10, 3615-3635 (2018).

24. Oae, S., Watanabe, Y. \& Fujimori, K. Biomimetic oxidation of organic sulfides with TPPFe (III) Cl/Imidazole/Hydrogen peroxide. Tetrahedron Lett. 23, 1189-1192 (1982).

25. Groves, J. T. \& Viski, P. Asymmetric hydroxylation, epoxidation, and sulfoxidation catalyzed by vaulted binaphthyl metalloporphyrins. J. Org. Chem. 55, 3628-3634 (1990).

26. Marques, A., Matteo, Md \& Ruasse, M. -F. Remarkable efficiency of iron (III) versus manganese (III) tetraphenylporphyrins as catalysts for fast and quantitative oxidation of sulfides into sulfones by hydrogen peroxide. Can. J. Chem. 76, 770-775 (1998).

27. Marques, A., Marin, M. \& Ruasse, M. -F. Hydrogen peroxide oxidation of mustard-model sulfides catalyzed by iron and manganese tetraarylporphyrines. Oxygen transfer to sulfides versus $\mathrm{H}_{2} \mathrm{O}_{2}$ dismutation and catalyst breakdown. J. Org. Chem. 66, 7588-7595 (2001).

28. Baciocchi, E., Gerini, M. F. \& Lapi, A. Synthesis of sulfoxides by the hydrogen peroxide induced oxidation of sulfides catalyzed by iron tetrakis (pentafluorophenyl)porphyrin: Scope and chemoselectivity. J. Org. Chem. 69, 3586-3589 (2004).

29. Pires, S. M. G. et al. Biomimetic oxidation of organosulfur compounds with hydrogen peroxide catalyzed by manganese porphyrins. Appl. Catal., A-Gen. 439-440, 51-56 (2012).

30. Pires, S. M. G. et al. Oxidation of organosulfur compounds using an iron (III) porphyrin complex: An environmentally safe and efficient approach. Appl. Catal., B-Environ. 160, 80-88 (2014).

31. da Silva, G. et al. A green and sustainable method for the oxidation of 1,3dihydrobenzo $[c]$ thiophenes to sulfones using metalloporphyrin complexes. Catal. Commun. 56, 68-71 (2014).

32. Alemohammad, T., Rayati, S. \& Safari, N. Highly selective and efficient oxidation of sulfide to sulfoxide catalyzed by platinum porphyrins. J. Porphyr. Phthalocyanines 19, 1279-1283 (2015).

33. Crich, D., Hutton, T. K. \& Ranganathan, K. Is there a homolytic substitution chemistry $\left(\mathrm{S}_{\mathrm{H}} 2\right)$ of sulfones? J. Org. Chem. 70, 7672-7678 (2005).

34. Wang, Y., Li, Y. \& Jiang, X. Sulfur-center-involved photocatalyzed reactions. Chem. Asian J. 13, 2208-2242 (2018).

35. Gurria, G. M. \& Posner, G. H. Photochemical deoxygenation of aryl sulfoxides. J. Org. Chem. 38, 2419-2420 (1973).
36. Jenks, W. S., Taylor, L. M., Guo, Y. \& Wan, Z. Photochemistry of dibenzothiophene-S,S- dioxide: Reactions of a highly constrained biradical Tetrahedron Lett. 35, 7155-7158 (1994).

37. Wan, Z. \& Jenks, W. S. Photochemistry and photophysics of aromatic sulfoxides 2 . Oxenoid reactivity observed in the photolysis of certain aromatic sulfoxides. J. Am. Chem. Soc. 117, 2667-2668 (1995).

38. Gregory, D. D., Wan, Z. \& Jenks, W. S. Photodeoxygenation of dibenzothiophene sulfoxide: Evidence for a unimolecular S-O cleavage mechanism. J. Am. Chem. Soc. 119, 94-102 (1997).

39. Nag, M. \& Jenks, W. S. Photochemistry and photophysics of halogensubstituted dibenzothiophene oxides. J. Org. Chem. 69, 8177-8182 (2004).

40. Lucien, E. \& Greer, A. Electrophilic oxidant produced in the photodeoxygenation of 1,2-benzodiphenylene sulfoxide. J. Org. Chem. 66, 4576-4579 (2001)

41. Thomas, K. B. \& Greer, A. Gauging the significance of atomic oxygen $\left[\mathrm{O}\left({ }^{3} \mathrm{P}\right)\right]$ in sulfoxide photochemistry. A method for hydrocarbon oxidation. J. Org. Chem. 68, 1886-1891 (2003).

42. Nakai, M., Furukawa, N. \& Oae, S. Photolysis of methyl benzenesulfonate in methanol. Bull. Chem. Soc. Jpn. 45, 1117-1119 (1972).

43. Shiraishi, Y., Hirai, T. \& Komasawa, I. Identification of desulfurization products in the photochemical desulfurization process for benzothiophenes and dibenzothiophenes from light oil using an organic two-phase extraction system. Ind. Eng. Chem. Res. 38, 3300-3309 (1999).

44. Shiraishi, Y., Tachibana, K., Hirai, T. \& Komasawa, I. Photochemical production of biphenyls from oxidized sulfur compounds obtained by oxidative desulfurization of light oils. Energy Fuels 17, 95-100 (2003).

45. Korang, J., Grither, W. R. \& McCulla, R. D. Photodeoxygenation of dibenzothiophene S-oxide derivatives in aqueous media. J. Am. Chem. Soc. 132, 4466-4476 (2010).

46. Samokhvalov, A. Desulfurization of real and model liquid fuels using light: photocatalysis and photochemistry. Catal. Rev. Sci. Eng. 54, 281-343 (2012).

47. McCulla, R. D. \& Jenks, W. S. Deoxygenation and other photochemical reactions of aromatic selenoxides. J. Am. Chem. Soc. 126, 16058-16065 (2004) in note 38.

48. d'Alessandro, N. et al. Oxidation of dibenzothiophene by hydrogen peroxide or monopersulfate and metal-sulfophthalocyanine catalysts: an easy access to biphenylsultone or 2-(2'-hydroxybiphenyl) sulfonate under mild conditions. New J. Chem. 27, 989-993 (2003).

49. Fujimori, K., Fujiwara, S., Takata, T. \& Oae, S. Importance of axial ligand in meso- tetraphenylporphinatoiron (III) promoted $\mathrm{N}-\mathrm{O}$ and $\mathrm{O}-\mathrm{O}$ bonds cleavages. Tetrahedron Lett. 27, 581-584 (1986).

50. Huang, X. \& Groves, J. T. Oxygen activation and radical transformations in heme proteins and metalloporphyrins. Chem. Rev. 118, 2491-2553 (2018).

51. Riemer, D. et al. $\mathrm{CO}_{2}$-catalyzed efficient dehydrogenation of amines with detailed mechanistic and kinetic studies. ACS Catal. 8, 11679-11687 (2018).

52. Maldotti, A. et al. Photochemistry of iron-porphyrin complexes. Biomimet. Catal. Coord. Chem. Rev. 125, 143-154 (1993).

53. Schilling, W., Riemer, D., Zhang, Y., Hatami, N. \& Das, S. Metal-free catalyst for visible-light-induced oxidation of unactivated alcohols using air/oxygen as an oxidant. ACS Catal. 8, 5425-5430 (2018).

54. Chen, J. \& Browne, W. R. Photochemistry of iron complexes. Coord. Chem. Rev. 374, 15-35 (2018).

55. Hu, C., Noll, B. C. \& Scheidt, W. R. Sulfoxide as a ligand in iron (II) porphyrinates: S- or O-bound. Inorg. Chem. 46, 8258-8263 (2007).

56. Arima, K. et al. The photochemistry of thiophene S-oxides. Photochem. Photobiol. Sci. 4, 808-816 (2005).

57. Nakayama, J., Hiraiwa, S. \& Fujihara, T. J. Photolysis and photo-oxidation of 3,4-di-tert-butylthiophene 1-oxide. J. Sulfur Chem. 29, 243-250 (2008).

58. Squires, T. G. et al. Preparation, characterization, and flash vacuum pyrolysis of dibenz $[c, e][1,2]$ oxathiin 6-oxide (biphenylene sultine). J. Org. Chem. 46, 2373-2376 (1981)

59. Huang, Z., Lumb, J. P. \& Phenol-directed, C. -H. functionalization. ACS Catal. 9, 521-555 (2018)

60. Duan, S., Xu, Y., Zhang, X. \& Fan, X. Synthesis of 2, 2'-biphenols through direct $\mathrm{C}(\mathrm{sp} 2)-\mathrm{H}$ hydroxylation of [1,1'-biphenyl]-2-ols. Chem. Commun. 52, 10529-10532 (2016).

\section{Acknowledgements}

This work was dedicated to the memory of István E. Markó. We thank the Hundred Talents Program of the Chinese Academy of Sciences, the Fonds National pour la Recherche Scientifique (FNRS - ERA No. R 50.02.11F) and Chinese Scholarship Council (CSC fellowship to Y.-Z. L.) for the financial support, thank Dr. Koen Robeyns (Université Catholique de Louvain) and Prof. Luc Van Meervelt (KU Leuven) for the X-Ray analysis of 13e, thank Prof. Nuno Maulide (University of Vienna), Prof. Huawu Shao and Prof. Wei Jiao (both from Chengdu Institute of Biology) for their valuable suggestions, thank Prof. Michael Singleton (Université Catholique de Louvain), Dr. Ian Hazelden and Prof. John F. Bower (both from University of Bristol) for correction of the paper. 


\section{Author contributions}

I.M. and X.-F.M. designed the research. X.-F.M. and Y.-Z.L. synthesized the catalysts and the substrates. X.-F.M. conducted substrate screening experiments and derivation of sulfinic ester. Y.-Z.L. and L.D. carried out the control experiments. J.Z. performed the computational studies. I.M. and X.-F.M. co-wrote the paper. All the authors discussed the results and commented on the paper.

\section{Competing interests}

The authors declare the following competing interests that one patent has been registered (201910893751.3), another patent has been granted (CN104277870B).

\section{Additional information}

Supplementary information is available for this paper at https://doi.org/10.1038/s41467020-14522-7.

Correspondence and requests for materials should be addressed to X.M.

Peer review information Nature Communications thanks Xuefeng Jiang and the other anonymous reviewer(s) for their contribution to the peer review of this work.
Reprints and permission information is available at http://www.nature.com/reprints

Publisher's note Springer Nature remains neutral with regard to jurisdictional claims in published maps and institutional affiliations.

(c) (i) Open Access This article is licensed under a Creative Commons Attribution 4.0 International License, which permits use, sharing, adaptation, distribution and reproduction in any medium or format, as long as you give appropriate credit to the original author(s) and the source, provide a link to the Creative Commons license, and indicate if changes were made. The images or other third party material in this article are included in the article's Creative Commons license, unless indicated otherwise in a credit line to the material. If material is not included in the article's Creative Commons license and your intended use is not permitted by statutory regulation or exceeds the permitted use, you will need to obtain permission directly from the copyright holder. To view a copy of this license, visit http://creativecommons.org/ licenses/by/4.0/.

(C) The Author(s) 2020 